Marquette University

e-Publications@Marquette

$1-1-2015$

\title{
The Philosophy of the Marburg School: From the Critique of Scientific Cognition to the Philosophy of Culture
}

Sebastian Luft

Marquette University, sebastian.luft@marquette.edu

Published version. "The Philosophy of the Marburg School: From the Critique of Scientific Cognition to the Philosophy of Culture," in New Approaches to Neo-Kantianism. Eds. Nicolas de Warren and Andrea Staiti. New York: Cambridge University Press, 2015: 221-239. Publisher link. (C) 2015 Cambridge University Press. Used with permission. 


\title{
The philosophy of the Marburg School: from the critique of scientific cognition to the philosophy of culture
}

\author{
Sebastian Luft
}

\section{Introduction}

The Marburg School of Neo-Kantianism is, besides the Southwest School, the most widely known and most influential school formation to emerge within the broad movement of Neo-Kantianism in the latter third of the nineteenth century. ${ }^{1}$ The school consisted of the twin stars Hermann Cohen (1842-1918) and Paul Natorp (1854-1924), with the younger Ernst Cassirer (1874-1945) as their satellite. Perhaps more than in any other philosophical grouping, the term "school" used to designate this cluster of philosophers merits attention. For its core members insisted that their project consists, essentially, of a unified weltanschaulich outlook on life whose basic commitments its followers must share. This was the manner in which the school was organized by its founders and by which they granted entrance to novices. As a tightly knit philosophical community, it has become paradigmatic for other groupings in the twentieth century, such as the Phenomenological Movement, the Vienna Circle or the Frankfurt School, who all tried, despite their own tendencies, to emulate this "school spirit."

Yet, the core tenets of this school are for the most part misrepresented. This is not surprising given the plethora of their writings and the lack of a real "manifesto." ${ }^{2}$ The contours of an overarching vision can only be gleaned through an overview of the publications stemming from the

1. To deflect possible criticism from the start, when I speak of "the Marburg School," I mean essentially Hermann Cohen, Paul Natorp, and Ernst Cassirer, and I exclude other philosophers working at the University of Marburg, such as Nicolai Hartmann or Hans-Georg Gadamer, who wrote his dissertation under Natorp.

2 Natorp's short Philosophie (Natorp 2008) can serve as an introduction to the main aims of the Marburg School. However, published in 19r1, it comes rather late in the life of the school and at a time in Natorp's life when his own paradigms had begun to shift. 
Marburg School, and not just its most popular writings, which lie in the philosophy of science. Given the predominant reception of the writings in this area, to introduce the philosophical principles and intentions driving the Marburg School, one has to confront a widespread misunderstanding head-on. In most presentations, the (Neo-)Kantianism of the Marburg School is treated as a narrowed form of Kant's philosophy. Allegedly, it reduces Kant's transcendental philosophy to a theory of naturalmathematical science, thereby relegating philosophy to a "handmaiden of the sciences." Kant's critical system becomes whittled down to an epistemology of natural-scientific cognition. A main concern in presenting this school must be a rejection of this erroneous reading, which is understandable only in light of the writings that were most widely read.

While it is true that the theory of scientific cognition the Marburgers formulated is an important aspect of this school, it would be misleading to see their main intentions exhausted in a theory of science. Instead, the main intention of this school was from the outset a broadening of the critique, both in method as well as scope. Formulaically, "the critique of reason becomes the critique of culture," as Cassirer announces in the first volume of his Philosophy of Symbolic Forms in 1923 (Cassirer 1954: I: II). But it is mostly overlooked that when Cassirer issues this "battle cry," he merely repeats the sentiment that inspires the school as a whole, starting from Cohen and Natorp. Such a critique, however, cannot do without a look at the effort of the sciences that work on different aspects of cultural life. As Natorp emphasizes, what is sought is "a truth which, armored with the impenetrable steel of the most genuine, most durable science, should at the same time be fit to satisfy not calculating reason, but to answer to the most secret, innermost doubts and questions of the soul" (Natorp 2008: 22). ${ }^{3}$ This concept of science is the target of criticisms that claim that science is an alienation from life and that culture is nothing but the indifferent field of inauthentic existence.

To sketch a grand vision of this school is the task of this chapter. The school's scope is, in effect, so great that it goes beyond that of Kant's architectonics, such that the designation "Neo-Kantian" is inadequate. It is no exaggeration to say that this school presents one of the most encompassing philosophical visions to arise in the tradition of classical German philosophy. Having modified and updated Kant's critical philosophy, having taken in Hegel's philosophy and the dimension of the historical, having witnessed the dominance of scientific positivism in the latter half of

\footnotetext{
3. All quotations from the German original are translated by the author.
} 
the nineteenth century, and having observed other Neo-Kantian tendencies attempting to counter the dominance of such a positivism, the Marburg School, in the late Cassirer, self-consciously situates itself between Kant and Hegel. It is one of the last great synthesizing attempts in the Enlightenment tradition before the advent of postmodernism. But, as contemporary thought has moved beyond such a radical stance, there are reasons to believe that there will be more sympathy for this "Marburg vision" today. It has the power to rival or complement other attempts that consider modernism an "unfinished project" rather than a quaint dream that is ausgeträumt.

As these preliminary reflections make clear, I treat the Marburg School as a unified philosophical vision. This is not to say that all members agreed on every aspect. Hence, it will be necessary to trace the steps that led, first, from Kant to Cohen, who laid out the first systematic position that defined the Marburg School. Yet, both Natorp and Cassirer were dissatisfied with Cohen's position the moment it went beyond a philosophical justification of the exact sciences. The subtle moves on the part of Natorp away from Cohen are a story of their own, ${ }^{4}$ though Natorp remained in strong outward unity with Cohen. This "closing of ranks" is explicable only through the intellectual and political landscape of the time. Cassirer, who never lived in Marburg and was, for that reason, often not considered part of this school, was unconcerned with such political games and expanded Cohen's scope, while remaining within the general framework of the Marburg School. Thus, the full-blown shape of the Marburg School as a philosophy of culture can be seen in Cassirer.

Hence, in the first section of this chapter, I discuss the general framework of Kant's question as to the conditions of the possibility of synthetic a priori cognition and how it takes on the concrete task of philosophical work with respect to the existing factum of the sciences. The latter is the starting point for the Marburgers. To repeat, the most important aspect of their philosophical efforts is their expansion of Kant's critique of reason into a critique of culture. A critique of scientific culture is but the beginning. But, to understand this transformation of the Kantian project into that of Marburg Neo-Kantianism, I discuss some key moves that occurred in Cohen in order to bring about this novel project. In the second section, I will trace the move from Cohen's "critical" idealism to Cassirer's

4 See the seminal study by H. Holzhey, Cohen und Natorp, 2 vols. (Basel and Stuttgart: Schwabe, 1986), who details the philosophy of Cohen and Natorp both in their collaboration as well as in their differences (including a great amount of archival material). 
"symbolic" idealism. Here, too, I confine myself to the main moves occurring in Cassirer in order to reconstruct his philosophy of the symbolic. In the third section, I will unfold the full-blown philosophy of culture as it is laid out in Cassirer's Philosophy of Symbolic Forms, including his teleological vision for humankind. In a conclusion, I will spell out what I believe could be the legacy of the Marburg School for contemporary efforts in philosophy and culture writ large. This legacy has lived on, in peculiar ways, in "Neo-Neo-Kantians," but it has been forgotten that it flourished in Marburg a century ago.

\section{From transcendental to critical idealism: the factum of the sciences}

Kant's Critique of Pure Reason is an exercise in theoretical philosophy (epistemology) and in this function an investigation into the nature, capacity, and limits of knowledge. Kant also dubs this investigation a "tractate on method" since the task of critique involves concrete steps to establish the fact that we have true cognition. "Real" rational cognition is, as Kant is proud to have discovered, synthetic a priori, as our reason is capable of expanding our knowledge without the aid of experience. Hence, the task Kant sets for himself is to establish how this cognition comes about. In the First Critique, this presentation is synthetic, in that Kant presents step by step the contributions of the two stems of knowledge, sensibility and understanding. The possibility of sensibility is explained, in the Aesthetics, through the doctrine of space and time as forms of intuition. The Analytic discusses the manner in which the understanding applies concepts (categories of pure reason) to intuitions. The crucial step beyond an explanation of this fact (quid facti) is the question as to how we are justified in making a priori claims about objects of experience (quid facti). In the Prolegomena, however, Kant opts for a different manner of presentation, the analytic one, starting out from the factum of existing cognition and inquiring into the conditions of the possibility of its comingabout. Both manners of presentation supposedly reach the same desired goal; their difference is merely heuristic.

It is the analytic path of the critique that the Marburgers preferred. The reason for this is the acknowledgment of the factum of synthetic a priori cognition, not as it is established in the abstract, but as it is applied in the mathematical exact sciences. As factum, as the result of the process of being made (facere) by scientific thought, it is to be explained as already existing. The working out of this factum was carried out in what Cohen calls Kant's 
"transcendental method," a term that would become the method of the Marburg School, though this phrase is not found in Kant. One of Cohen's key interpretive claims regarding Kant's philosophy was, accordingly, that "the transcendental method was conceived in a meditation on Newton's Philosophiae Naturalis Principia Mathematica" (Cohen 1987: 94). For Cohen, Kant's achievement lay not so much in the abstract possibility of synthetic a priori cognition; instead, this achievement was fueled by the fascination that this type of cognition was being obtained in mathematical natural sciences, insofar as mathematics is applied to nature, thereby enabling and effectively creating a priori cognition. How this was possible and how to justify this fact was, according to Cohen, Kant's main concern.

Hence, the factum of reason in the abstract was concretely worked out in the factum of science (das Faktum der Wissenschaft). This insight is not Kant's discovery, however, but a restatement of the Western tradition. The factum of science is the key to understanding the Western project of philosophy, to Cohen, and Kant merely took up this thread that began with Plato, who placed philosophy on the secure foundation of science. This entire tradition can only be adequately appreciated when seen through the prism of the constant proximity of philosophy and science beginning with Plato's idealism, which is "the methodological generator of science" (Cohen 1987: xvii). Science, however, is an ongoing process by which thought, through the production of new ideas and hypotheses, conquers reality. What reality is can only be obtained under this assumption, that we can only comprehend what we, as Kant defines transcendental idealism, "lay into things" through our reason. Hence, the connection between science and philosophy as idealism is a necessary one:

The factum of science is the basic assumption that philosophy makes and without which it cannot begin. Therefore, this factum is not dogmatically assumed but is rather the methodological presupposition. If all thinking, as production of ideas, unfolds and constructs itself in hypotheses, then it is necessary to understand as the first hypothesis: that of science itself. (Cohen 1987: 41)

Thus, while scientific progress is ongoing, what remains constant is the production of hypotheses, which are confirmed or falsified. In this activity, the sciences are in effect idealistic, as they bring, in broad generality, reality under ideas (concepts, theories). Only then can one truly speak of experience of reality. Cohen's original reading of Kant's Theory of Experience (the title of his first work on Kant), in his attempt to "lay a new ground for the Kantian doctrine of the a priori" (Cohen 1987: ix), is that the experience 
Kant means is the experience on the part of the scientist, when she conceives the numbers and laws under which nature stands. This is an ongoing activity of thought, not in the generational sequence of researchers, but in terms of the logical content of the scientific achievements (Cohen is a fierce enemy of a psychologistic reading of scientific progress). The factum is, as Natorp says, a fieri, something being made, a making on the part of thinking subjects with regard to the logical progress (Natorp 2013: 39). As fieri, this progress is never-ending. Reality as fully logically penetrated is the unattainable "thing in itself."

Looking back at Kant's transcendental idealism, what has thus happened here? Transcendental idealism is the claim that we undertake the Copernican experiment to view objects insofar as they conform to our cognitive capacities and that we never experience the thing in itself but always only insofar as it appears to us. In the Marburg reading, modern natural science is already enacting this idealism, unbeknownst to itself. The phenomena that science ascertains are the laws of nature that we impose based on our reason. Philosophy, then, has no task of its own, it can have no territory of its own where it can perform its sui generis work. All it can do is reconstruct the work in the sciences, not attempt to do something over and beyond it. It is, thus, a critique of the factum of the sciences; the critique is a critique of reason as it is enacted in scientific progress. As such, Cohen conceives transcendental idealism as critical idealism with the express purpose of critiquing thought as it becomes enacted in the sciences. This confirms the close tie between philosophy and science that is the signature of Western thought. Kant merely brought this insight to the clearest expression.

How does philosophy do this, concretely? What remains as the task of philosophy (the "transcendental method")? Cohen describes the latter thus:

Critique, thus, means first and foremost the warning: not to identify or place on equal footing philosophy with mathematics or natural science. Philosophy's task is not to create things or - as the seductive and infamous saying goes, borrowed from mathematics - to 'construct' them, but instead merely to understand and to test how the objects and laws of mathematical experience are constituted. But the critique yields, along with this warning, at the same time the insight and the consolation that mathematical natural science does not merely rest on mathematics and experience, but itself partakes in philosophy. The critique teaches to see and explore this partaking, and the philosopher exploring this feels in the object of his critique the spirit of his own spirit. (Cohen 1987: 734f.) 
What happens now with one of the central demands of Kant, the establishment of a priori cognition, if science is an ongoing process that never ends? Did not Kant claim to have discovered the totality of categories and the principles by which we apply the former to nature? Here we find what is perhaps the most original idea developed by the Marburg School. If science is an ongoing process, then the original categories that Kant discerns will not suffice for the purpose of giving expression to rational cognition. But the option of simply dropping the demand of a priori cognition cannot simply be accepted, since this would open the door to relativism. The solution can only be to reconceive the a priori. As Cohen states, "new problems will require new presuppositions. The necessary idea of the progress in science has as a necessary presupposition ... the idea of the progress of pure cognitions" (Cohen 1977: 396). The a priori becomes, thus, dynamic, insofar as new insights require new concepts that are necessary for the time being but which can be modified or expanded (or perhaps rendered obsolete) as the progress ensues. This is the attempt to reconcile the claim to objective knowledge with the dynamic progress of scientific cognition, which is rational, not merely empirical. As Cassirer states:

The "fact" of science is and will of course remain in its nature a historically developing fact. If in Kant this insight does not yet appear explicitly, if his categories can still appear as finished "core concepts of reason" in number and content, then the modern development of critical and idealistic logic [i.e., Cohen] has made this point perfectly clear. The forms of judgment mean for it the unified and active motivations of thought, which course through the manifold of its particular formations and are continually put to use in the generation and formulation of new categories. (Cassirer 1994a: 18)

In Cassirer's rendition of this concept, one can distinguish, more precisely, two levels of a priori, a strict and a dynamic one, as he says in a letter to Schlick:

I would call "a priori" in the strict sense merely the idea of "unity of nature," that is, of the lawfulness of experience as such or perhaps, more concisely, the "distinctness of attribution" [Eindeutigkeit der Zuordnung] ... But this principle of distinctness itself is, to me, indeed, more than just a "convention" or an "inductive generalization": it is, to me, an expression of "reason," of Logos itself. (Cassirer 2009a: 50-51, from October 23, 1920)

Beyond the strict sense of a priori, there is a dynamically evolving web of concepts that are necessary for a given phenomenon and for the time being,

s On this conception and its defense see M. Friedman, The Dynamics of Reason (Stanford: CSLI Publications, 2001). 
the "very best bets" we have at a given time, with the knowledge that we might have better or different bets at a later stage of scientific development. This conception of the a priori retains the transcendental nature of Kant's philosophy (necessary conditions of possibility of cognition), while acknowledging that science makes progress and ever-expands its boundaries. The idea of scientific progress is, however, purely "logical," concerning the progress of rational cognition, not a matter of empirical discovery. But to the Marburgers, new empirical discoveries are only then real ("experienced") when they are understood rationally. Everything else would be a fallback into a naïve realism that purports to be in touch with the "things themselves."

Now if cognition can only be attained in the sciences, what is left for philosophy to do other than to "attest to" (beglaubigen) the latter, as Cohen interprets the justificatory aspect of critique? At this point the critique of philosophy as the "handmaiden of the sciences" seems to stick. Can philosophy do anything but "follow carrying the train of lady science" (Cassirer 2004: 358)? And if so, does this not mean that philosophy as a discipline of its own has become obsolete? The Marburgers were, of course, well aware of this reproach. I will return to this point in the conclusion. For now, we can utilize the proximity between philosophy and science to set out the broad lines of the Marburg School, returning to the project of a philosophy of culture.

Critical idealism is most carefully worked out in Cohen's theory of scientific cognition. But, according to the original intention, the transcendental method should be put to work in all areas of culture. Culture is defined as "the entire work of humanity in which the latter produces and forms ever higher [hinaufbildet] what is peculiar to humanity itself" (Natorp 2008: 42). The areas of culture, such as what is made by human beings - facere does not only take place in science - follow the Kantian canonical distinction into epistemology, ethics, and aesthetics. The philosophy of culture, then, is the logic of each cultural formation, where the transcendental method reconstructs the logics that produce each cultural region. Such a particular logic can, to Cohen, only reconstruct the logical structure of that cultural region, not its empirical or material elements. But just as in epistemology, the logical concepts underpinning ethics and law can only be derived from an existing science. The paradigm of starting out, in each region, from the "factum of the sciences," means that in ethics one must start out from legal science, jurisprudence, which is the point of crystallization of legal affairs. The grounding of ethics, hence, can only occur through a reconstruction of the concepts 
and theories of an existing legal theory. Ideally, there is, as an ideal natural science, an ideal legal science as factum that is constantly under way, yet with the status of its laws and procedures as a priori.

Where it is plausible that natural science works towards an ideal status, such a claim might strike one as less than convincing in the realm of jurisprudence. While Cohen might have had in mind a universal doctrine of universal human rights, there are undeniably very different legal systems based on different legal traditions, which are unlikely ever to converge. But the transcendental method becomes even less convincing when Cohen declares that art history is the scientific factum from which one has to derive the logic in the realm of aesthetics. Such a rather artificial approach raises the question whether such a search for a logical structure starting from a scientific factum can do justice to the wealth and multiplicity of culture. When the Marburg School, hence, is chastised for having a "scientistic" or "logicistic" outlook on culture, this critique is justified, the moment one goes beyond a theory of scientific cognition. It is at this point that Cassirer departs from his teacher and moves into his own philosophy of culture, centered on the concept of the symbolic.

\section{From critical idealism to symbolic idealism: the ubiquity of the symbolic}

Cassirer accepted Cohen's critical idealism with respect to the logic of science, but clearly regarded this approach as inadequate when it came to culture as a whole. This insight was itself reached, interestingly, in his early work in the philosophy of science, Substance and Function, of rio. Cassirer's main philosophical contribution after his historical work on the development of modern science in Das Erkenntnisproblem (volumes I and II appeared in 1906 and 1907) was his recognition that a profound paradigm shift had occurred in modern science, more precisely in the process of concept formation. Scientists, in antiquity, believed that concepts mirrored things in the world. What underlay this assumption, as well as the concomitant conception of objects, was Aristotle's substance ontology. Accordingly, concepts were substance concepts. This Aristotelian manner of concept formation has endured into modernity. Gradually, however, this process was paralleled and subsequently replaced by a different one, which conforms to the "transcendental" reading of modern science according to the Marburgers. Modern science has already been performing the Copernican turn insofar as the theories are not read off of the things (themselves) but are a rational creation; they are what we lay into 
nature through reason. Accordingly, concepts scientists use to express lawful structures under which nature stands are mental creations, not read off of substances "out there" (recall a concept such as "atom"). These concepts are themselves the reflection of a different ontology. Such an ontology cannot be about substances existing independently of us. Instead, things are what they are to us to the extent that we construct them through our rational labor. This labor consists in the creation of theories and, more essentially, concepts, which do not stand as substances in and of themselves. Instead, concepts are relational, and the process of concept formation in modern science is the creation of a string (Reihe) of relations. Cassirer concludes his historical overview of this process:

Thus it becomes clear that all concept-formation [in the new paradigm] is bound to a certain form of string-formation [Reihenbildung]. We call an intuited manifold grasped and ordered conceptually when its members do not stand alongside one another in isolation [beziehungslos], but when it comes forth according to a creative basic relation from a certain beginning member in necessary relation ... according to a principle. (Cassirer 1994b: 19f.)

This standing-in-relation according to a principle of order is captured in the mathematical concept of function, $f(\mathrm{x})$. The concept in modern science is a "rule for the connection of the individual" (Cassirer 1994b: 25), whereby the "generality of a string-principle is the characteristic moment of the concept" (Cassirer 1994b: 26). Gradually, in modern science, the "logic of the mathematical functional principle" (Cassirer 1994b: 27) comes to confront and replace the concept of substance. The functional concept can also be called a symbol:

The basic concepts of every science, the means by which it poses its questions and forms its solutions, no longer appear as passive representations of a given entity, but as self-created intellectual symbols. (Cassirer 1954: 1: 5)

To the extent that Cassirer explains the modern use of concepts as formed through a functional principle, rendering them symbols, he is adding greater detail to Cohen's basic doctrine. But Cassirer, by the time he has developed his philosophy of the symbolic in the 1920s, goes beyond Cohen and his own analysis of 1910 with the claim that this symbolism is at work not only in the realm of scientific cognition, but in all functions of "spiritual life." Spiritual life writ large is symbol-creating, and the symbolic is ubiquitous:

Every genuine basic function of spirit has in common with cognition this one trait that an original-formative, not just imitative, power is inherent in 
it. The latter does not just express passively what is there, but contains a spiritual energy of its own through which simple entities of intuition receive a certain "meaning," a peculiar ideal content. This goes for art as it does for cognition, for myth as well as religion. They all live in peculiar image-worlds in which not merely something empirically given mirrors itself, but which they produce according to an independent principle. Each of them creates its own symbolic forms which are, not identical to, but in their own spiritual origin on a par [ebenbürtig] with intellectual symbols. (Cassirer 1954: I: 9)

The ubiquity of the symbolic, beyond scientific concept formation, is the basic idea of the philosophy of symbolic forms. Cassirer's conception of the symbol-creating spiritual energy is the antithesis of any representationalism, according to which (as Rorty claims) the human mind is the mirror of nature. In Cassirer's use of the mirror image, the opposite holds; reality is the mirror of the human mind, which is not exhausted in producing cognition alone. Cognition with its scientific method is one form of spiritual energy; other spiritual energies, those at work in myth, religion, art, have their own functional structures, generating their own symbolic forms. The task of philosophy is to perform the "transcendental method" on them, not in Cohenian fashion searching for each respective factum of science, but in reconstructing the functional principle by which each spiritual energy creates and shapes the functional nexus governing each form. This is a task philosophy cannot do without leaning on empirical research in these different areas, but this is different from choosing a factum of science of these cultural realms for a reconstruction of their "logics." The functional principle at work in different forms of culture cannot be reduced to a logic; "function" displaces Cohen's rigid conception of logic.

The term "spiritual energy" is not to invoke some form of mysticism; it is the result of a reconstruction starting regressively from the different spheres of meaning that art, myth, etc. are. They are the facta into whose "conditions of possibility" must be inquired. But these different spheres of meaning are not simply there. They are created, they are the results of different types of intuition, of which Kant merely discerned the abstract forms of space and time. Intuition is not passively receiving but actively forming. There is a plurality of experiencing the world, and each type of viewing sees something different. Mythical space is different from the space of modern physics, as it is different from the space of art or religion. This is not an empirical statement about the psychological capacities of the human species, but a transcendental statement concerning the culture-forming capacities of the mind. Kant's Transcendental Aesthetics becomes pluralized, but each account of a particular intuition remains thereby transcendental, clarifying 
the constitutive principles governing each functional nexus. Cassirer illustrates this plurality of seeing with an example:

I grasp in [a serpentine line] the character of a certain ornament, which is linked up for me with a certain artistic meaning and an artistic signification ... Once again the form of the observation can change, insofar as that which at first presented itself to me as a pure ornament, can reveal itself as the bearer of a mythical-religious meaning. ... And to this form of seizing and internal acquisition we can juxtapose, with deliberate sharpness, another one ... While the aesthetically contemplating and savoring individual gives himself over to the intuition of the pure form, where to the religiously touched person a mystical meaning is disclosed in this form; the form that stands before one's eyes can also serve for thought as an example of a purely logical-conceptual structural nexus ... Where the aesthetical direction of viewing perhaps saw Hogarth's Line of Beauty, the mathematician's gaze sees the image of a certain trigonometric function, e.g., the image of a sine curve, while the mathematical physicist sees in the same curve the law of a periodic wave. (Cassirer 2009b: $97 \mathrm{f}$.)

The concrete task of the philosophy of the symbolic is to describe the "symbolic logic" in each case of symbolic formation. An individual thing is construed as a symbol; it makes sense only in a context of other things; hence the symbol is the "throwing together" (sym-ballein) of the individual and the general. Its meaning is contextual and has a different meaning in different symbolic gazes. This amounts to the universalization of Kant's transcendental idealism: the phenomenon becomes the symbol, and to account for it means to reconstruct the "logic," the functional principle in each symbolic form. Myth, art, religion, science all have their own structural principles and manners of functioning. ${ }^{6}$ Thus we arrive, from critical idealism, at symbolic idealism.

The sum total of these symbolic forms is culture; it is the totality of the deeds on the part of humans, "for the content of the concept of culture cannot be isolated from the basic forms and directions of spiritual producing: 'being' is always only to be grasped in 'doing'" (Cassirer 1954: I: II).? Culture itself, then, is itself a functional concept that can be defined only through the deeds that bring it about, and not through a formal definition, which would render it a substantial "thing." This is why the philosophy of the symbolic can never be a finished "system." Rather, the systematic

\footnotetext{
${ }^{6}$ What they have in common is what one can call the triad of the symbolic: the function of impression, expression, and presentation, but these functions work differently in the different forms; see Cassirer 2009b: 70-73.

"One of Cassirer's favorite authors is Goethe. Recall that Faust translates "logos" as "Tat" (deed); see Faust I, v. 1237.
} 
character of this philosophy must be demonstrated in the method of reconstructing the functional nexuses and in distinguishing the basic nexuses from one another. The concrete method of this philosophy is, thus, phenomenological. ${ }^{8}$

Cassirer was not able to complete his "system," since his fleeing from the Nazis forced him to change plans for publishing the Philosophy of Symbolic Forms. After he had moved from Germany to England, from there to Sweden and finally to the United States, his relocations and encounters with different intellectual milieus caused his interests to shift. His philosophical plans were far from completed when he died in 1945 . This can be seen from the many additions and novel ideas that Cassirer produces after 1933. There is no denying that Cassirer left many critics wanting and many questions unanswered. Cassirer never doubted the truth of the project of a critique of culture as an analysis of the symbolic in its manifold expressions. By way of discussing some critical questions, I turn to the metaphilosophical significance of a critique of culture.

\section{The complementaristic plurality of culture and humanity's self-liberation in culture}

The purpose of the philosophy of symbolic forms as a critique of culture is to give a rich account of the plural expressions of culture while keeping such an account within the boundaries of transcendental philosophy. The philosophy of symbolic forms is no empirical science, though it can and must rely on material provided by scientific disciplines. One will never find Cassirer discussing a problem without reference to scholarship; e.g., linguistics in the case of language, and anthropology in the case of mythical consciousness. ${ }^{9}$ However, the claim is a philosophical one, to provide the basic functional structure of each symbolic form, its particular logic, which is the respective condition of the possibility of viewing, thereby creating, the world, "its" world. While there can be no system that would claim to be complete - culture is an ever-evolving process - the question remains, what is the overall aim of this philosophy? If it was said that the concrete method is phenomenological (descriptive), one can point out that no description is

${ }^{8}$ Cassirer oftentimes confirms his alliance with phenomenology; see Cassirer 2009b: 7, 98-99. For a comparison between Cassirer and Husserl see S. Luft Subjectivity and Lifeworld in Transcendental Phenomenology (Evanston: Northwestern University Press, 20rt), 235-266.

9 See Cassirer 1979: 80. "We have no orher way to find [the rules governing each form] than to ask the special sciences, and we have to accept the data with which we are provided by them." 
naïve and without presuppositions. What is, thus, the guiding clue underpinning Cassirer's analyses?

The plurality and richness of culture cannot be subjected to the benchmark of science. Conversely, the philosophy of culture makes it clear that a merely empirical account of culture will not suffice, because such an account is prone to a cultural relativism. But what is the status of the symbolic forms themselves in the framework of a transcendental account? It is curious that Cassirer, when it comes to the number of symbolic forms, rarely gives a "deduction" or a justification of why he mentions the ones he does and not others. Moreover, his enumerations vary and sometimes include other forms besides language, myth, religion, art, and cognition. And it is even more curious to note that he devotes systematic studies only to language, myth, and cognition, and in this order. What is the rationale for his procedure? Cassirer is not consistent and fully clear here, and there is no denying these systematic gaps.

Part of this lack of full exposition can be chalked up to Cassirer's inability to finish his philosophy due to his biography. The fact that he is not consistent in enumerating the symbolic forms - in later years, he mentions technology and economy - can be countered by reminding us of the functional nature of culture, that culture cannot be defined from above and that it is possible that new forms arise in the process of culture. Indeed, such a discussion about the arrival of new forms of culture can be an interesting exercise in cultural philosophy (is, for instance, the Internet a new symbolic form?). As he says, "human civilization necessarily creates new forms, new symbols, new material things in which the life of man finds its external expression" (Cassirer 1979: 139). But there is one important point where Cassirer's wavering gives rise to a more serious concern.

On the one hand, Cassirer insists that he wants to give an account of the richness of "spiritual activity" where each spiritual power has its sui generis "logic" that cannot be compared to others, and it would be a metabasis if one symbolic form were measured by the standard of another (as Cohen did when measuring all other forms with the standard of science). Thus, the symbolic forms are irreducible to one another. The philosophy of symbolic forms is an account of these symbolic forms without such an overreaching from one form to another. They are, in this scenario, ordered horizontally, displaying no hierarchy. Rather, they complement one another, together yielding a richer sense of culture (Cassirer quotes Hegel, das Ganze ist das Wahre). It is the task of the philosophy of the symbolic to "spell out of phenomena different symbols and, so to speak, 
different alphabets of thought that do not contradict each other but complete one another" (Cassirer 1979: 76).

On the other hand, statements as to the relation of the different forms to one another in terms of a hierarchy are not absent. For one, Cassirer is unfailingly clear on one point, the systematic locus of myth. Myth is the first form of spiritual and cultural development, which is primitive (though not irrational) and is overcome through higher forms of cultural expression. Religion, language, and science "conquer" myth and relegate it to a form of unenlightened pre-cultural existence. It is a stage of human development to which one may not return in a developed culture. The fact that myth is made to re-enter the arena of culture is his critique of modern fascism (cf. Cassirer 1946). This marks him as standing in the tradition of the Enlightenment. Conversely, Cassirer speaks of science as the highest expression of human spirit and as the purpose and end-goal of culture. While all symbolic forms "possess their own distinctive type of 'universal validity' ... the clearest and best example of such 'universal validity' continues, in good Marburg style, to be given by the language of mathematical exact science." These passages make him vulnerable to the charge that despite the emphasis on all cultural forms being equal, they are, at the end of the day, subordinate to scientific theory and its logical ideal of universal validity in a lingua universalis, and to the critique that he remains aloofly disrespectful of our facticity and our finitude. In this way, one may summarize Heidegger's position against Cassirer during the Davos standoff.

There is, as mentioned, no denying that one finds conflicting passages in this respect. A solution can only be to spell out what Cassirer should have unambiguously said in light of this contradiction. Should scientific conduct be interpreted as the highest form of human culture? Surely a scientific positivism or unalloyed belief in scientific progress is not Cassirer's sentiment. Despite his admiration for modern science, and his intimate knowledge thereof, Cassirer is nonetheless more aptly placed on the "humanistic" side of the "two cultures." Or perhaps better, Cassirer's position is best described as "synthetic" in wanting to do justice to both traditions, in that the humanistic aspect of culture should not be left unaccountable to reason and rational critique, and in that natural-scientific reason should not operate in the way of a cold-hearted technology. Thus, while the philosophy of culture was described as proceeding by a

${ }^{\circ}$ M. Friedman, A Parting of the Ways: Carmap, Cassirer, and Heidegger (Chicago: Open Court, $2000), 152$. 
descriptive method, the normative aspect of critique must not be overlooked. To subject culture to critique, then, must not be understood in the way of a cold rational look at culture, and hence the exclusive search for logical structures, but in the way in which Natorp describes rationality, as answering to the deepest questions of mankind.

The "critique of culture" may thus not be seen as the call to rationally "scan" the different cultural forms as to their "deep" rational structures. Rather, what must be emphasized is that culture is the correlate of the common humanity that unites us; in all cultural forms we find "ultimately the 'same' human being that we always continually encounter in the development of culture, in thousands of manifestations and in thousands of masks." ${ }^{\prime \prime}$ This insight amounts to acknowledging the emancipatory power of culture as the self-liberation of the human being in and through culture. The task of the critique of culture is to make understandable that culture, in all of its forms (starting centrifugally from myth), is the gradual acquisition of freedom. This critique "rejects the conception that mind submits to an outward fate. Mind must realize and actualize its own freedom in order to possess it, and the whole work of culture is this very process of self-realization" (Cassirer 1979: 89). Yet, mind is to be found, not in an absolute state, but in the refractions of the various forms of culture, which are forms of our own making and spaces where alone we can be human beings. Thus, the description of the symbolic forms is at the same time a prescription of the common core of humanity to which we all ought to belong. The animal rationale is, thus, defined in a more encompassing sense as animal symbolicum and the ethical ideal of this vision is that freedom can only be obtained in culture; that culture is not the inhibitor of freedom, but its condition of possibility. Cassirer characterizes the "promise and hope" (1979: 90) of the distinctly Marburg-infused philosophy of culture thus:

It hopes to come to a sort of grammar and syntax of the human mind, to a survey of its various forms and functions, and to an insight into those general rules by which they are governed. By this we may be able to understand in a better way the koinon kosmon of humanity, that common world in which each individual consciousness participates and which it has to reconstruct in its own way and by its own efforts. (Cassirer 1979: 89)

The philosophy of culture, thus, has no task over and above this realization, it is not a symbolic form of its own, but it is the logic of the symbolic

"Quoted in Friedman, A Parting of the Ways, I54. 
in its richness of expression. It makes us understand that there is not and ought not to be any life outside of culture, and that culture is both our space and ours to create responsibly.

\section{Conclusion. The legacy of Marburg: the collaboration of philosophy and science; the emancipatory function of culture}

Regarding the legacy of the Marburg School, let me mention one aspect in conclusion, where I believe its efforts bear resemblance to some of today's philosophical concerns.

Let me return to the critique of philosophy as the "handmaiden of the sciences." The critique consists in the claim that, with this allencompassing ideal of culture and the insistence that philosophy cannot do without the individual sciences dealing with the different forms of cultural expression, philosophy is indeed relegated to nothing other than the former's handmaiden. I think it is fair to say that many contemporary philosophers would bristle at this notion of philosophy. In order to correctly assess what philosophy is to accomplish, one can compare the Marburg School with another form of Neo-Kantianism, namely Robert Brandom's inferentialism. I cannot delve deeper into one of the most impressive philosophies of our day, nor do I claim that Brandom is the only contemporary philosopher who could serve as example here. I only wish to point out one contemporary parallel to the Marburg position.

In philosophy's task of "making explicit" the discursive commitments we undertake when we engage in the "social practices of giving and asking for reasons" (Brandom 200I: 92), Brandom rejects the role of philosophy as being the "queen of the sciences" ("philosophy is at most $a$ queen of the sciences, not the queen" (93)). Indeed, philosophy plays no "foundational role with respect to other disciplines" (ibid.) and in this sense, Brandom expressly embraces the image of the "handmaiden" (ibid.), and he describes the task of philosophy as follows:

For what we do that has been misunderstood as having foundational or methodological significance is to provide and apply tools for unpacking the substantive commitments that are implicit in the concepts deployed throughout the culture, including the specialized disciplines of the high culture. Making those norms and inferences explicit in the form of claims exposes them for the first time to reasoned assessment, challenge, and defense, and so to the sort of rational emendation that is the primary process of conceptual evolution. But once the implicit presuppositions and consequences have been brought out into the daylight of explicitness, the 
process of assessment, emendation, and evolution is the business of those whose concepts they are, and not something philosophers have any authority over or expertise regarding. (Brandom 2001: 92-93)

This definition of the task of philosophy has interesting similarities with that of the Marburg School. The Marburgers would agree that philosophy cannot, and should not, provide an ultimate foundation, it cannot be "first" philosophy, since it cannot make itself independent of the sciences which discover the concepts and functions of the regions they are sciences of. As Cohen says, philosophy is no Grundlagenwissenschaft, a science of foundations. But as handmaiden, it also develops the tools for "rational emendation," which precisely is critique, but necessarily critique of something that functions implicitly through norms, and this is culture. Directly addressing the issue of whether philosophy is the torch- or train-bearer of the sciences, Cassirer maintains that there can be a third alternative. Philosophy's task cannot consist in

mediating the inner battles that always again arise in science and to silence them through hasty solutions. Rather, it stands in the midst of these battles, it cannot and wishes not to be anything but the fellow combatant [Mitstreiterin] in these. Instead of overcoming the oppositions through the command of thought or attempting to reconcile them through a mere compromise, it must rather make these visible in their full seriousness and gravity. (Cassirer 2004: 358)

As combatant in these battles, philosophy equally has the task of making explicit the functional principles guiding the symbolic forms, which is not something individual sciences can do on their own, but which is not something entirely above and beyond them either. Philosophy merely has the task of making explicit what goes on implicitly in the cultural activities. What is made explicit in the essentially self-reflective intellectual activity philosophy is the fact that culture is the expression of the common humanity that we share. Surely, the philosophy of symbolic forms "makes things explicit" in its own manner, as explained in this essay, but in this division-of-labor concept of philosophy, "Marburg" bears striking similarity to "Pittsburgh." But understood in the right way, this is not a reproach that should put philosophers working in this mode on the defensive. Instead, it is the healthy balance any philosophy must strike when it acknowledges that it cannot operate in a vacuum but in a culture rich with creative work, part of which is carried out in the sciences, while not ceding its position to naturalism.

The moral demand is that this process of culture becomes everexpanded, keeping barbarism at bay, while knowing that the human 
being is a "crooked piece of timber" that can never be made straight. Emancipation from "self-incurred tutelage" can only come through partaking in culture, which is not anybody's private achievement, but the product of "spirit." Thus, the Marburg School situates itself, in Cassirer, consciously between Kant and Hegel. 